\title{
Editorial: Internal Migration - Spatial Analysis and Policy
}

\author{
John Stillwell
}

Received: 2 January 2014 / Accepted: 3 January 2014 /

Published online: 12 January 2014

(C) Springer Science+Business Media Dordrecht 2014

This special issue of themed papers has its origins in a set presentations that were delivered at an International Geographical Union (IGU) conference on Applied GIS and Spatial Modelling hosted by the Centre for Spatial Analysis and Policy, School of Geography at University of Leeds in June 2013 and held at the Hilton Hotel in the city centre. The issue contains two papers that are essentially methodological in their focus, two papers providing empirical analyses of temporal trends and spatial patterns of relatively long-distance migration in two very different parts of the world, and one paper that considers the relationship between inter-regional migration and selected explanatory variables and has a policy orientation.

These five papers represent a microcosm of quantitative research on internal migration. Collectively, the papers address some of the key questions in contemporary migration studies: How do we address the scale and zonation problems when comparing migration between countries? What evidence of migration dynamics is available from time series trends in China and what has been the role of the state in the changes taking place in the last 30 years? What changes in migration intensities and flow patterns have been observed in the UK in the last inter-censal decade? How important is it to introduce variable weights when systematic bias is observed in large survey samples of individual migration flow records? How do we attempt to quantify the effects of inequality reduction policies on inter-regional migration flows?

In times when international immigration captures press headlines and governments debate the pros and cons of increasing levels of migration exchange across the globe, it is necessary to remind ourselves of the importance of the phenomenon of internal migration in almost all countries of the world. The magnitudes, spatial patterns and explanatory factors underpinning aggregate and subgroup internal migration differ from country to country and the IMAGE (Internal Migration Around the GlobE) project, funded by the Australian Research Council (ARC), has the explicit objective of providing league tables for a suite of internal migration indicators associated with migration intensity, distance, connectivity and impact. Another objective of the IMAGE project is to address one of the major challenges for those involved in cross-

J. Stillwell ( $\square)$

School of Geography, University of Leeds, Leeds LS2 9JT, UK

e-mail: j.c.h.stillwell@leeds.ac.uk 
national comparisons of sub-national migration: the problem of comparing migrations flows measured between spatial units of differing sizes and shapes in different countries, the so-called modifiable areal unit problem (MAUP). In order to facilitate comparative analysis, the IMAGE studio has been developed for the computation of global and local indicators of migration flows, including the calibration of a spatial interaction model that allows the impact of distance on migration to be quantified. The framework that underpins the IMAGE studio is outlined in the first paper by John Stillwell and colleagues from the IMAGE team, together with explanation of the functionality that each of its subsystems provides and illustration of the various user interfaces. One of the four subsystems of the studio involves the facility to aggregate the initial set of regions for which data has been captured and input (called basic spatial units) into larger regions (called aggregated spatial regions) but to do this repeatedly so that the migration indicators and model parameters can be computed at different spatial scales. Moreover, at each spatial scale, i.e. where the number of aggregate spatial regions is the same, the aggregation algorithm generates different configurations of regions. The user can choose how many different spatial configurations are generated as well as the number of scale steps. The results presented in the paper for four selected northern European countries give some interesting insights into the scale and zonation effects of the MAUP when considering the frictional effect of distance on migration.

The IMAGE studio has been used by the authors of the two papers that follow to calculate local and global indicators for migration between basic spatial units in the UK and China. In 2010, Nik Lomax was awarded an ESRC Case studentship in 2010 to work in partnership with the Office for National Statistics (ONS) to estimate a consistent time series of migration flows between local authority districts in the UK as well as (immigration and emigration) flows between these districts and the rest of the world. Whilst the estimation method is summarised briefly in the paper (more details can be found in Lomax et al. 2013), it is the former set of internal migration flows that are the focus of attention in this paper although a proportion of these flows do cross the international boundaries that define the four home nations that constitute the UK and might therefore be considered as international in some quarters. The IMAGE studio has been used to compute statistics that demonstrate how internal migration propensities and distances declined during the 2000s and the headline message is the fall in the level of counterurbanization taking place in the second half of the decade as the global financial crisis took hold. The flows are usefully summarised by using a district classification framework distinguishing urban from rural areas combined with those located either in the north or the south. The classification shows us the importance of the transition over the decade from a situation where both urban and rural areas of the north were gaining net migrants from urban and rural areas in the south to a new situation in which the urban north is losing migrants to both the urban and the rural south and the high rates of net migration gain in the rural north from the rural south have diminished significantly. The second half of the 2000s has seen a significant change in the UK's pattern of internal migration and the paper concludes with some discussion of the potential implications for local authority policy and service provision.

Changing spatial patterns of internal migration are also a feature of China's population in recent decades. In the third paper, Ye (Oscar) Liu and colleagues argue that Chinese central government policy, through economic reforms and the relaxation of migration 
controls, together with labour market forces, have had a profound effect on internal migration in China. Using various migration indicators, including migration efficiencies, the paper traces the development of the surge of aggregate migration flows from the interior provinces to the coastal regions as a result of the reforms since the 1980s. The analyses are based on a continuous time series of 5-year transition migration data extracted from three censuses (in 1990, 2000 and 2010) and two large mid-decade sample surveys (in 1995 and 2005). Analyses by age group show how the younger working age cohorts in 2000-2005 have become much more mobile that older cohorts when compared with 1985-1990 and more responsive to inter-provincial differentials in labour market conditions. Moreover, while the less educated in China have tended to migrate to the coastal provinces in large numbers, the more educated have been attracted by the knowledge-based and advanced service industries in the major growth centres of Beijing and Shanghai.

In the UK, whilst the decadal census Special Migration Statistics (SMS) provide valuable 1-year aggregate data on directional migration flows at different spatial scales and whilst inter-censal flows can be estimated from administrative registers and surveys, as analysed in the paper by Lomax and colleagues, sources of microdata on migration beyond the Samples of Anonymised Records (SARs) are few and far between. It is therefore refreshing to hear that microdata extracted from a large sample of the population captured by a commercial organisation is providing results that throw new light on the relative importance of certain explanatory variables or selective influences. Since the characteristics of Acxiom's Research Opinion Poll (ROP) have been reported elsewhere (Thomasm, Gould and Stillwell 2012), the focus of the fourth paper in this series by Michael Thomas and colleagues is on demonstrating whether it is necessary to use variable weights to handle the problem of sample bias and whether the weighting procedure makes any difference when calibrating the parameters of a binary regression model that quantifies the associational patterns of key demographic, socio-economic and behavioural or lifestyle variables. The results are counterintuitive in the sense that, generally speaking, weighting appears to make little difference to the signs of the parameters with similar sets of results being generated from both weighted and unweighted models. In addition, the results indicate that the sample is dominated by relatively short-distance residential mobility for which housing tenure is critical rather than relatively long-distance internal migration for which labour market factors tend to become more important. The alignment of the results with other findings reported in the migration modelling literature provides further evidence with which to claim that this data set has genuine value as an alternative source of migration data.

The final paper in this special issue on 'internal migration' directs us, once again, to recognise that scale is critical in migration studies. In this case, the author, Adam Dennett, uses a data set of inter-regional flows between European Union (EU) countries estimated using spatial interaction models These are essentially international flows but we take the liberty of regarding them as being internal flows as far as the EU is concerned. The focus of the paper is not on the estimation methodology, which is reported elsewhere (Dennett and Wilson 2013), but on the relationship between the size of flows estimated between origin and destination NUTS2 regions and two indicators of economic conditions, the ratio of the origin to destination unemployment rate and a similar ratio for the standardised GDP per capita. As with the previous paper, logistic regression is used to produce odds ratios which are plotted for pairwise flows ordered 
into deciles according to the size of flow and averaged. The results provide evidence that at the extremes of migration behaviour, i.e. where there are very large flows or very small flows, big differences between average unemployment rates or GDP PPS per person between the origin and destination regions can make those large or small flows several times as likely, but a change in the inequality ranking of one decile can have a dramatic effect on the size of flows. This is particularly relevant for policy makers because they can begin to understand the implications for migration of policy measures designed to reduce regional inequality on the one hand, but also appreciate the scale of growth that is required to have any pronounced effect on migrants from relatively poor regions (in Romania and Bulgaria, for example) to relatively wealthy regions (in the UK or Germany, for example), on the other.

Acknowledgments Thanks are due to Graham Clarke for organising the IGU meeting in Leeds, to the contributors to this special issue for their efforts in drafting and revising their manuscripts and also to the anonymous referees who have provided detailed comments and valuable guidance on how to improve the papers for the benefit of the readers who I hope will discover a final product that is both useful and interesting.

\section{References}

Dennett, A., \& Wilson, A. (2013). A multi-level spatial interaction modelling framework for estimating interregional migration in Europe. Environment and Planning A, 45, 1491-1507.

Lomax, N., Norman, P., Rees, P., \& Stillwell, J. (2013). Subnational migration in the United Kingdom: producing a consistent time series using a combination of available data and estimates. Journal of Population Research, 30(3), 265-288.

Thomas, M., Gould, M., \& Stillwell, J. (2012) Exploring the potential of microdata from a large commercial survey for the analysis of demographic and lifestyle characteristics of internal migration in Great Britain, Working Paper 12/03, School of Geography, Leeds University, Leeds. Online at: http://www.geog.leeds. ac.uk/fileadmin/documents/research/csap/12-03.pdf. 